\title{
Some solutions of the steady state diffusion of carbon dioxide through soils
}

\section{J. WESSELING}

Institute for Land and Water Management Research (I.C.W.), Wageningen, the Netherlands

\section{Summary}

Solutions have been given for the steady state diffusion of carbon dioxide through soils. The general diffusion equation (2) has been solved under the assumption that the relation between the ratio $D / D_{a}$ (= ratio coefficient of diffusion in soil and in air) and the fraction of airfilled pores is given by (4). The course of the $\mathrm{CO}_{2}$-production $\alpha$ in the soil profile is given by (5).

In the case of sprinkler irrigation, the moisture content throughout the profile is assumed to be constant (field capacity). The solution is given by (6).

If no sprinkler irrigation is applied, the solutions are given for the decrease of the air-content with the first and second power of the depth (eq. 9). For the first case the solution is given by eq. 20 and fig. 3, for the second case the solution is given by eq. 21 and fig. 4. The last two figures are based on a total $\mathrm{CO}_{2}$-production $\mathrm{B}=154 \mathrm{mg} \mathrm{m-2} \mathrm{hr-1}$.

\section{Introduction}

Air can be supplied to the soil either by hydrodynamical flow owing to differences in pressure or by diffusion owing to differences in concentration gradients. BucKINGHAM (1904) pointed out that the hydrodynamical flow is of little importance for the aeration of the soil and that air is supplied mainly by diffusion. Various other investigators (van Bavel, 1951, 1952), BlaKe and Page (1948), Penman (1940), Romell (1922), TAYloR (1949) arrived at the same conclusion.

Diffusion of gas through a porous medium takes place according to the general equation

$$
\frac{\partial q}{\partial t}=\frac{\partial}{\partial z}\left(D \frac{\partial c}{\partial z}\right)+\alpha
$$

where

$q=$ amount of diffusion in $\mathrm{gmol} \mathrm{cm}^{-2} \mathrm{sec}^{-1}$

$t=$ time in seconds

$z=$ distance in $\mathrm{cm}$

$D=$ coefficient of diffusion in $\mathrm{cm}^{2} \mathrm{sec}^{-1}$

$c=$ concentration of gas in $\mathrm{gmol} \mathrm{cm}^{-3}$

$\alpha=$ amount of gas (gmol) produced or adsorbed per unit time and unit volume. It is taken negative in the case of adsorption and positive in the case of production.

Received for publication 5th December, 1961. 
Since the changes in saturation of the soil are generally slow, as compared with the time in which the air in the upper layer of the soil is changed by diffusion, the aeration of the soil may be described by the equation for the steady state diffusion, derived from eq. 1 :

$$
\frac{\partial}{\partial z}\left(D \frac{\partial c}{\partial z}\right)+\alpha=0
$$

For the problem of aeration of the soil this equation is for homogeneous profiles subject to the boundary conditions:

$$
\begin{array}{ll}
c=C_{0} & z=0 \\
\frac{\partial c}{\partial z}=0 & z=L
\end{array}
$$

$C_{0}$ being the concentration of the gas in the free atmosphere.

Solutions of the equation are mainly dependent on $\alpha$ and $D$ which are, in general, decreasing with depth. In the next sections some solutions will be given in which $\alpha$ and $D$ are taken functions of the soil profile and the root depth.

\section{The coefficient of diffusion}

Diffusion must take place through airfilled pores, since the diffusion through water is about $10^{4}$ times as small as that through air. The quantity of airfilled pores in the soil, therefore, is a very important factor. BucKINGHAM (1904) found a proportionality of $D$ with the second power of the fraction of airfilled pores $p$. For $p<0,7$ Penman (1940) found the relationship $D / D_{a}=0,66 p$, where $D_{a}$ is the diffusion coefficient in air. Penman's observations, however, lie all above $p=0,35$, those of Buckingham above $p=0,25$. On the other hand there are various data from Blake and Page (1948), Baver and FARNSwOrth (1940) and TAYlor (1949) where the diffusion coefficient is practically zero for $p$ ranging from 0,10 to 0,15 . The evidence that diffusion practically stops at $p=0,10$ agrees with experiments of WYCKOFF and BoTSET (1936) who found that the hydrodynamical permeability for air is also practically zero if the airfilled pore space becomes less than 0,10 . The values of $D / D_{a}$ obtained by Penman (1940), TaYlor (1949) and van Bavel (1952) are plotted against $p$ in FIG. 1. Linear adjustment according to VAN UVEN (1946) gives for the relation between $D / D_{a}$ and $p$ :

$$
D / D_{a}=0,9 p-0,1
$$

This relation was also used by vaN DuIN (1956) and Wesseling (1957) in their calculations of aeration problems.

\section{The production of carbon dioxide}

A critical review of all kinds of observations about the production of carbon dioxide is given by WeSSELING (1957) and Wesseling and VAN WIJK (1958). Romell (1922) states that the $\mathrm{CO}_{2}$-production in arable land during summer ranges from 0,55 to 


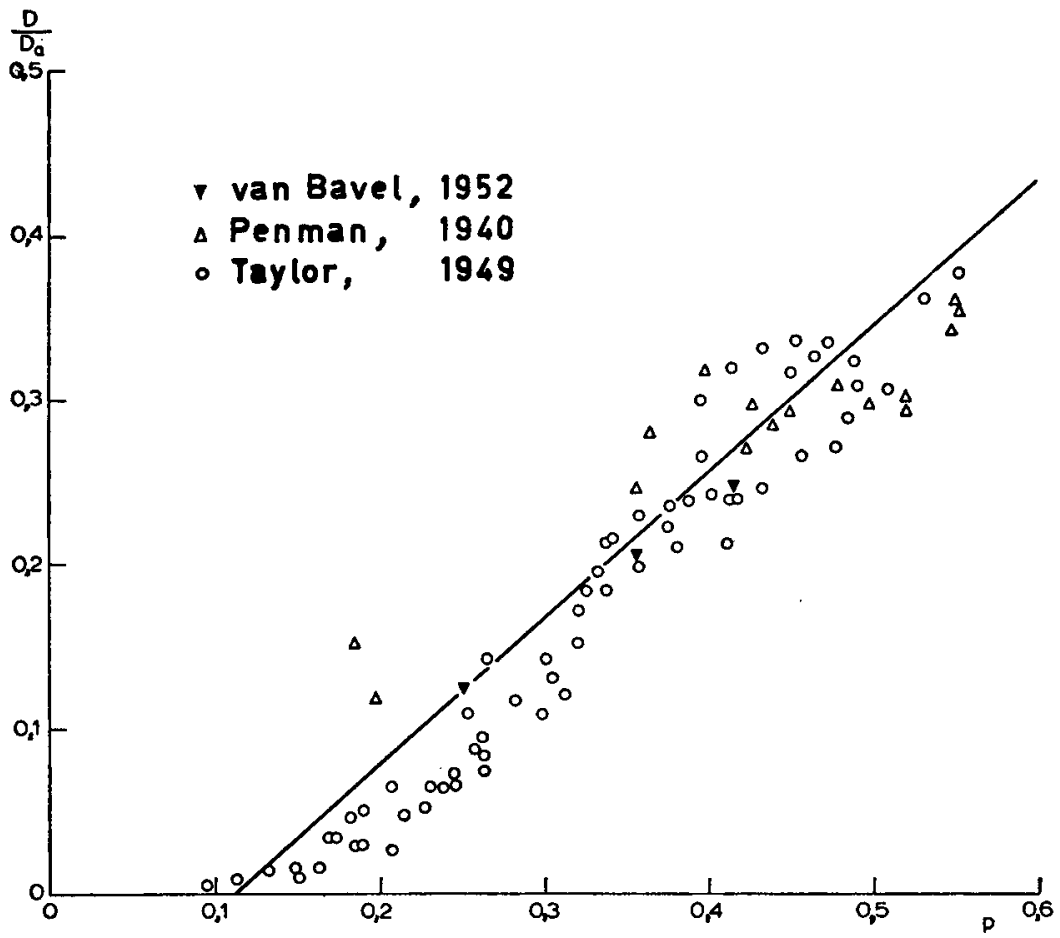

FIG. 1. The relation between $D / D_{a}$ and the fractions of air-filled pores $p$ after experiments from van Bavel (1952), Penman (1940) and TaYlor (1949)

$0,82 \mathrm{~g} \mathrm{~m}^{-2} \mathrm{hr}^{-1}$. KOEPF (1954) gives values of 0,15 to $0,40 \mathrm{~g} \mathrm{~m}^{-2} \mathrm{hr}^{-1}$. WURMBACH (1934) gives for pasture land 8,8 to $11,9 \mathrm{~g} \mathrm{~m}^{-2} \mathrm{hr}^{-1}$. According to LundegaARDH $(1924,1954)$ temperature is the main factor below $20^{\circ} \mathrm{C}$. At higher temperatures the moisture content of the soil will be the limiting factor. Also physical, chemical and biological properties of the soil will influence the uptake of $\mathrm{O}_{2}$ and the production of $\mathrm{CO}_{2}$.

For the calculation of the $\mathrm{CO}_{2}$-content of the soil not only the total production of $\mathrm{CO}_{2}$ but also the relative production in each layer of the soil will have to be known. In an earlier article (WESSELING, 1957) the present author found that the production for arable land on homogeneous soil profiles may be described by an equation, originally proposed by vaN DUIN (1956):

$$
\alpha_{z}=\alpha_{0}\left\{1-\left(\frac{q}{L}\right)^{1 / 4}\right\}
$$

where

$\alpha_{z}=$ the production of $\mathrm{CO}_{2}$ in $\mathrm{gmol} \mathrm{cm}^{-2} \mathrm{sec}^{-1}$ at a depth $\mathrm{z}$

$\alpha_{0}=$ the production in the top layer

$L=$ the depth at which the production is zero

In eq. 5 the varying amount of roots, bacteria, etc. in the soil will influence the production levels and the zero production depth. At the end of the growing season 
$L$ may be taken 90 to $125 \mathrm{~cm}$ dependent on the kind of crop. Taking a mean growing rate of the roots of $1 \mathrm{~cm}$ per day, the root depth at each moment during the growing season may be computed.

For grassland the production of $\mathrm{CO}_{2}$ mainly takes place in the upper 20 to $40 \mathrm{~cm}$ of the soil and may be taken equal throughout the profile. The same holds for shallow clay layers or humous sandy layers resting on a sandy subsoil in which the roots generally do not penetrate.

\section{Solutions of the diffusion equation}

RomeLl (1934) gives some solutions of eq. 2 with $\alpha$ constant or linearly decreasing with depth and $D$ constant throughout the profile. Similar solutions are given by vaN Bavel (1951) for homogeneous and layered soils. Further van Bavel (1951) and VAN Duin (1956) give solutions in which $a$ does not decrease linearly with depth. The last mentioned author uses eq. 5 for the decrease of $\alpha$.

In all solutions mentioned above the production of $\mathrm{CO}_{2}$ was assumed to be restricted to the upper layers of the soil. The constant value of $\mathrm{D}$ implies that the solutions are only valid for a constant moisture content of the soil. In the case of grassland or arable land, or soils with shallow rooting properties, the solutions may give a good deal of information about the $\mathrm{CO}_{2}$-concentration in these soils.

The penetration of roots, however, determines for a great part the possible extraction of water from the soil. In order to get information in how far root development may be restricted by high concentrations of $\mathrm{CO}_{2}$, diffusion and production of $\mathrm{CO}_{2}$ in the subsoil has to be taken into account. Then the simplification of a constant moisture content throughout the profile is not permissible, except in the case of sprinkler irrigation. Therefore the present author developed solutions of eq. 2 with a variable diffusion coefficient and $a$ decreasing with depth according to eq. 5 (Wesseling, 1957). These solutions, dealt within the next two sections, are made in such a way that they give the $\mathrm{CO}_{2}$-content at each depth, when only the total production of $\mathrm{CO}_{2}$ and the course of the moisture content of the soil profile are known.

\section{Aeration in the case of sprinkler irrigation}

In general it may be stated that crop production increases with decreasing soil moisture tension except in the case that aeration is the limiting factor. What must now be the minimum pore space of the soil in order to prevent damage from insufficient aeration? In other words, on what kind of soils sprinkler irrigation may be applied with respect to aeration?

The most unfavourable conditions during sprinkler irrigation occur when the soil is kept at field capacity. Taking the soil moisture content constant throughout the profile, the diffusion coefficient is constant. Using now the relation between $D / D_{a}$ and $p$ given in eq. 3 and a production according to eq. 4 , the solution of eq. 2 subject to the boundary conditions given in eq. 3 becomes

$$
c=C_{0}-\frac{a_{0}}{0,14(0,9 p-0,1)}\left\{\frac{1}{2} z^{2}-\frac{16}{45} z^{9 / 4} L^{-1 / 4}-0,2 L_{q}\right\}
$$

where $D / D_{a}=0,14 \mathrm{~cm}^{2} \mathrm{sec}^{-1}$ at $15^{\circ} \mathrm{C}$ and $C_{0}=0,03 \mathrm{~mol} \%$, is the concentration of $\mathrm{CO}_{2}$ in the air. 
The total production of $\mathrm{CO}_{2}$ will be given by

$$
\int_{0}^{L} \alpha_{z} d_{z}
$$

With the aid of eq. 5 integration gives

$$
\int_{0}^{L} \alpha_{0}\left\{1-\left(\frac{z}{L}\right)^{1 / 4}\right\} d q=\frac{1}{5} \alpha_{0} L=B
$$

Taking $\alpha_{0}=10^{-6} \mathrm{mg} \mathrm{cm}^{-2} \mathrm{sec}^{-1}$ independent of the root depth $L$, the course of the $\mathrm{CO}_{2}$-concentration in the soil according to eq. 6 is given in FIG. 2 for $p_{0}=0,15$ and 0,20 and $L=75,100$ and $125 \mathrm{~cm}$. For $p_{0}=0,20$ and a root depth $L=75 \mathrm{~cm}$, the $\mathrm{CO}_{2}$-concentration at a depth of $15 \mathrm{~cm}$ is $0,74 \%$.

FIG. 2. Course of the $\mathrm{CO}_{2}$-concentration in the soil in the case of sprinkler irrigation (moisture content is kept constant at field capacity) with $B=\frac{1}{5} \alpha_{0} L$ and $\alpha_{0}=10^{-6} \mathrm{mg} \mathrm{cm}^{-2} \mathrm{sec}^{-1} . L=75,100$ and $125 \mathrm{~cm}$

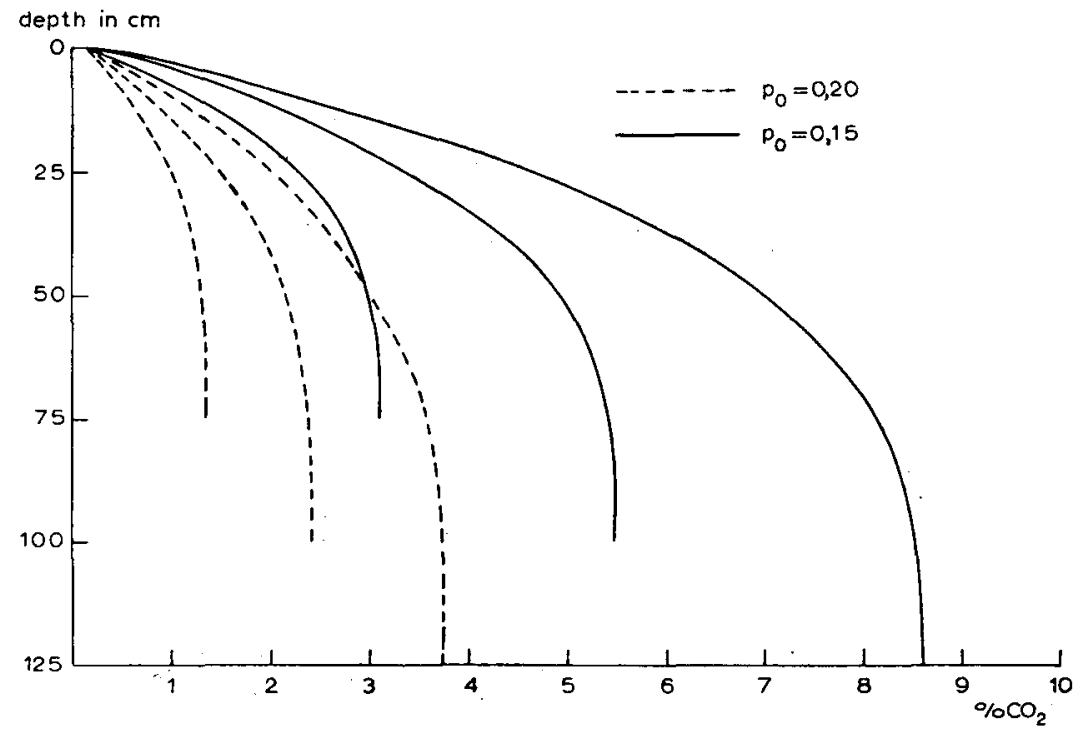

In investigations carried out by STOLP and WESTERHoF (1954) where the conditions were in agreement with the above mentioned conditions, aeration was no limiting factor. This is in good agreement with the criterion given by LuNDEgaARDH (1924, 1954) that the $\mathrm{CO}_{2}$-concentration may not exceed $1 \%$ at a depth of $15 \mathrm{~cm}$. It is, however, by no means sure that this criterion is right for all crops.

If the total production, the root depth and the moisture content at field capacity is known, the $\mathrm{CO}_{2}$-content of the soil may be derived from FIG. 2 by simply multiplying the concentration found in this figure, by the ratio of the exact $\mathrm{CO}_{2}$-production and the one that was introduced in this figure. 


\section{Aeration in other cases}

Without sprinkler irrigation the moisture- and air-content of the soil profile depends on the depth of the water table, the kind of soil, the evapotranspiration rate and the root depth of the crop. Generally, the moisture content will increase with depth and consequently the air-content will decrease in this direction. Now it is assumed that the air-content decreases according to

$$
p_{z}=p_{0}\left(1-a_{k} z^{k}\right)
$$

where the subscripts $z$ and $O$ indicate the depth. The value of $k$ is chosen 1 and 2 . Further $a$ is given four or five values corresponding with increasing air-gradients in the profile. The corresponding values of $L$ were computed from eq. 9 by taking $L=z$ where $p_{z}=0,1$, thus the diffusion taken zero when $p \leqslant 0,1$.

The values of $a, p_{0}$ and $L$ for which solutions are given are collected in TABLE 1 (WESSELING, 1957).

TABLE 1. Values of $L$ computed from eq. 9 for various values of $p_{0}$ and $a_{k}$. The value of $L$ is the depth where $p_{z}=0,1$

\begin{tabular}{|c|c|c|c|c|c|}
\hline$p_{0}:$ & 0,20 & 0,25 & 0,30 & 0,35 & 0,40 \\
\hline$a_{1} \cdot 103=4$ & 87,5 & 120,0 & - & - & - \\
\hline & 58,3 & 80,0 & 94,4 & 104,8 & 112,5 \\
\hline 8 & - & 60,0 & 70,8 & 78,5 & 84,4 \\
\hline 10 & - & - & 56,7 & 62,9 & 67,5 \\
\hline$a_{2} \cdot 103=4$ & 93,5 & 109,6 & 118,0 & 125,0 & 130,0 \\
\hline 6 & 76,5 & 89,5 & 97,4 & 102,3 & 106,0 \\
\hline 8 & 66,1 & 77,5 & 84,2 & 88,6 & 91,9 \\
\hline 10 & 59,2 & 69,3 & 75,3 & 79,4 & 82,1 \\
\hline 12 & 54,0 & 63,3 & 68,6 & 72,4 & 75,0 \\
\hline
\end{tabular}

A solution of the problem may be obtained in the following way.

Using eq. 5 for the $\mathrm{CO}_{2}$-production, we get by substituting the value of $\mathrm{B}$ from eq. 8 into eq. 5 :

$$
\int_{0}^{z} \alpha_{z} d_{z}=5 B\left\{\frac{z}{L}-\frac{4}{5}\left(\frac{z}{L}\right)^{5 / 4}\right\}
$$

By introducing the lower limit $p_{z}=p_{L}=0,1$, into eq. 4 we get:

$$
D_{z}=0,9 D_{a}\left(p_{z}-p_{L}\right)
$$

For $z=L$, eq. 9 becomes

$$
p_{L}=p_{0}\left(1-a_{k} L^{k}\right)
$$

Substituting now the values of $p_{z}$ and $p_{L}$ from eqs. 8 and 11 into eq. 6 and taking $D / D_{\circ}=0,14 \mathrm{~cm}^{2} \mathrm{sec}^{-1}\left(\right.$ at $\left.15^{\circ} \mathrm{C}\right)$ gives

$$
D_{z}=0,126 a_{k} p_{0}\left(L^{k}-z^{k}\right)
$$

With the aid of eqs. 19 and 13 the first integration of eq. 2 gives

$$
5 B\left\{\frac{\tau}{L}-\frac{4}{5}\left(\frac{z}{L}\right)^{5 / 4}\right\}=-D_{\tau} \frac{\partial c}{\partial z}+D_{0} \frac{\partial c}{\partial \tau_{\theta}}
$$


SOME SOLUTIONS OF THE STEADY STATE DIFFUSION OF CARB. DIOXIDE THROUGH SOILS

Because $\frac{\partial c}{\partial \tau}=0$ for $z=L$ and $D_{L}=(0)$ we have from eq. 14 :

$$
B=D_{0} \frac{\partial c}{\partial z_{0}}
$$

and eq. 14 becomes

$$
-D_{z} \frac{\partial c}{\partial z}=B\left\{1-5 \frac{z}{L}-4\left(\frac{z}{L}\right)^{5 / 4}\right\}
$$

Substituting the value of $D_{₹}$ from eq. 11 into eq. 16 then yields :

$$
\frac{\partial c}{\partial z}=-\frac{B\left\{-1+5 \frac{z}{L}-4\left(\frac{z}{L}\right)^{5 / 4}\right\}}{0,126 a_{k} p_{0}\left(L^{k}-z^{k}\right)}
$$

Integrating eq. 17 with the boundary condition $c=C_{0}$ for $z=0$ gives us

$$
c=C_{0}-\frac{B}{0,126 a_{k} p_{0}} \int_{0}^{\tau} \frac{-1+5 \frac{z}{L}-4\left(\frac{z}{L}\right)^{5 / 4}}{L^{k}-q^{k}} d q
$$

Taking now

$$
t=\frac{z}{L}
$$

we get for $k=1$ :

$$
c=C_{0}-\frac{B}{0,126 a_{1} p_{0}} \int_{t=0}^{t=\frac{\tau}{L}} \frac{-1+5 t-4 t^{5 / 4}}{1-t} d t=C_{0}+\frac{B I_{1}}{0,126 a_{1} p_{0}}
$$

and for $k=2$ :

$$
c=C_{0}-\frac{B}{0,126 a_{2} p_{0}} \int_{t=0}^{t=\frac{z}{L}} \frac{-1+5 t-4 t^{5 / 4}}{1-t^{2}} d t=C_{0}+\frac{B I_{2}}{0,126 a_{2} p_{0}}
$$

The values of $I_{1}$ and $I_{2}$ are given in TABLE 2 .

TABLE 2. Values of $I_{1}$ and $I_{2}$ from eq. 20 and 21 respectively, for various values of $t$

\begin{tabular}{lllllll}
\hline$t:$ & 0,0 & 0,2 & 0,4 & 0,6 & 0,8 & 1,0 \\
$I_{1}$ & 0 & 0,163 & 0,274 & 0,347 & 0,388 & 0,401 \\
$I_{2}$ & 0 & 0,149 & 0,236 & 0,284 & 0,309 & 0,316 \\
\hline
\end{tabular}


FIg. 3. Course of the $\mathrm{CO}_{2}$-concentration in the soil according to eq. 20. The air content in the soil decreases linearly with depth. The total $\mathrm{CO}_{2}$-production $B=154 \mathrm{mg} \mathrm{m}^{-2} \mathrm{hr}^{-1}$. Figures near curves indicate values of $a_{1}$ and $p_{0}$ respectively

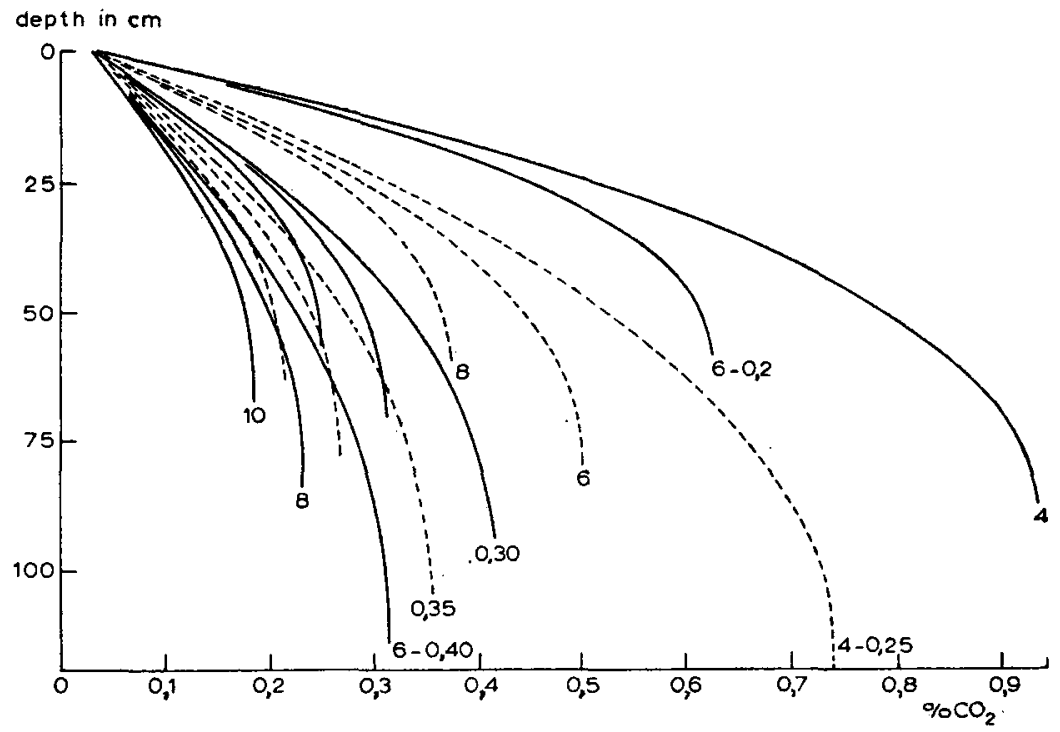

Fig. 4. Course of the $\mathrm{CO}_{2}$-concentration in the soil according to eq. 21. The air content in the soil decreases with the second power of the depth. The total $\mathrm{CO}_{2}$-production $B=154 \mathrm{mg} \mathrm{m}^{-2} \mathrm{hr}^{-1}$. Figures near curves indicate values of $a_{2}$ and $p_{0}$ respectively

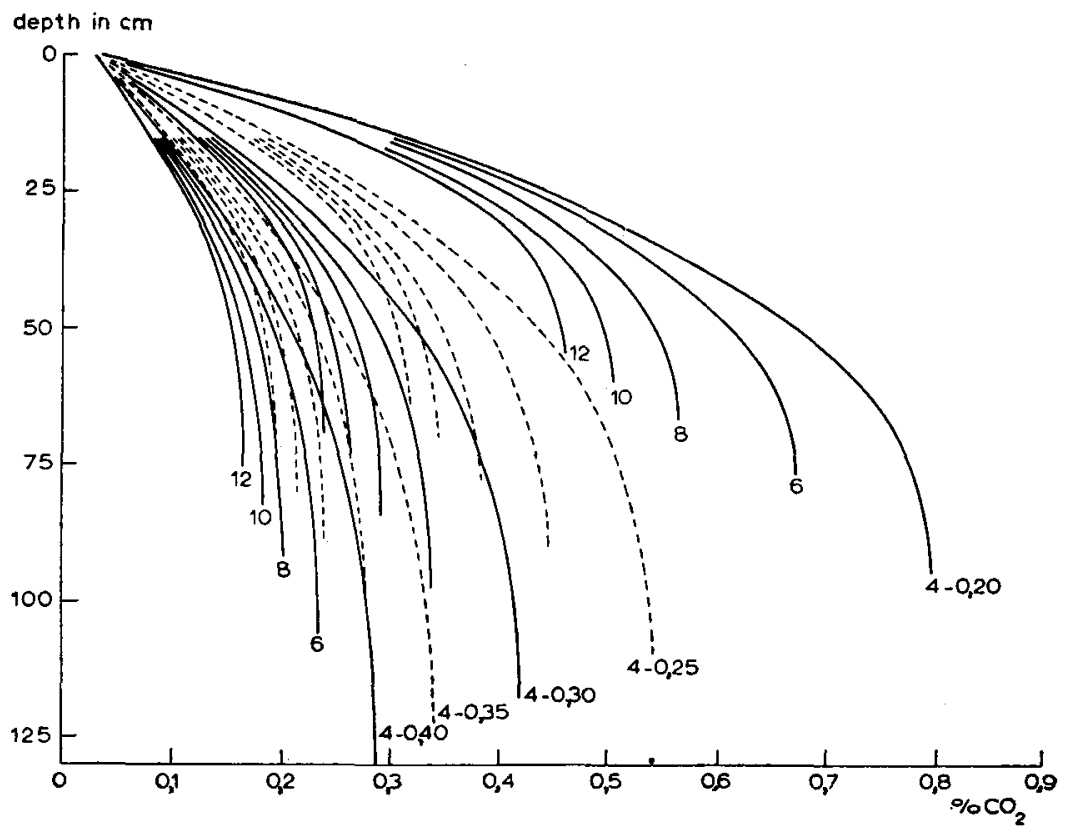


With the aid of the TABLES 1 and 2 and eqs. 19,20 and 21 , the $\mathrm{CO}_{2}$-concentration can be computed. This has been done for $k=1$ in FIG. 3 and for $k=2$ in FIG. 4 . In these graphs $B$ was taken $154 \mathrm{mg} \mathrm{m}^{-2} \mathrm{hr}^{-1}$. When the total $\mathrm{CO}_{2}$-production $B$, the root depth and the course of the moisture content is known, the $\mathrm{CO}_{2}$-concentration may be determined from these graphs by multiplying the $\mathrm{CO}_{2}$-content found in the graph by the ratio of the real $\mathrm{CO}_{2}$-production and that introduced in the graph used.

\section{Bavel, C. H. M. vaN}

BAVER, L. D., and

R. B. FARNSWORTH

BLAKE, G. R., and

J. B. Page

Buckingham, E.

DUIN, R. H. A. VAN

KoEPF, $\mathbf{H}$.

LUNDEGAARDH, $\mathrm{H}$.

Penman, H. L.

RoMell, L. G.

STOLP, D. W., and

J. J. WESTERHOF

TAYLOR, S. A.

UVEN, M. J. VAN

WESSELING, J. , and W. R. VAN WIJK

WURMBACH, $\mathbf{H}$.

WYCKHOFF, R. W., and H. G. BotSET

\section{I T E R A T URE}

1951 A soil aeration theory based on diffusion. Soil Sci. 72, 33-46.

1952 Gaseous diffusion and porosity in porous media. Soil Sci. 73, $91-96$.

1940 Soil structure effects on the growth of sugar beets. Soil Sci. Soc. Am. Proc. 5, 45-48.

1948 Direct measurement of gaseous diffusion in soils. Soil Sci. Soc. Am. Proc. 13, 37-42.

1904 Contributions to our knowledge of the aeration of soils. U.S.D.A. Bur. Soils Bull. No. 25.

1956 On the influence of tillage on conduction of heat, diffusion of air and infiltration of water in soil. (Dutch). Versl. Landbouwk. Onderz. No. 62.7.

1954 Untersuchungen über die biologische Aktivität des Bodens. Zeitschr. Acker- und Pflanzenbau. 98, 289-312.

1924 Der Kreislauf der Kohlensäure in der Natur. Gustav Fischer, Jena.

1954 Klima und Boden in ihrer Wirkung auf das Pflanzenleben. 4e Aufl. Gustav Fischer, Jena.

1940 Gas and water movement in the soil. J. Agric. Sci. 30, 437462 and $570-581$.

1922 Luftväxlungen i marken som ekologisk faktor. Medd. frän Statens Skoystörsöksanstalt 19, 125-361.

1954 Agricultural water management. (Dutch). Cultuurtechniek, Alg. Landsdrukkerij. The Hague, p. 20-48.

1949 Oxygen diffusion in porous media as a measure of soil aeration. Soil Sci. Soc. Am. Proc. 14, 55-61.

1946 Mathematical treatment of the results of agricultural and other experiments. 2nd ed. P. Noordhof N.V., Groningen.

1957 Some aspects of the water government in agricultural soils. (Dutch). Versl. Landbouwk. Onderz. No. 63.5.

1958 Soil physical conditions in relation to drain depth. Drainage Monograph. Chapter V-1. Am. Soc. of Agronomy.

1934 Beiträge zur Kenntnis der Bodenatmung und der Kohlensäurekonzentration in landwirtschaftlich genutzten Flächen. Wiss. Archiv für Landw. 10, 484-532.

1936 The flow of gas-liquid mixtures through unconsolidated sands. Physics. 7, 325-345. 